\title{
Avaliação nas aulas de espanhol como língua estrangeira no ensino superior: o que mudou com o ensino emergencial remoto?
}

\author{
Assessment in classes of Spanish as a foreign language in Brazilian higher education: \\ what has changed with emergency remote teaching?
}

\section{Evaluación en clases de español como lengua extranjera en la educación superior: ¿qué ha cambiado con la enseñanza remota de emergencia?}

\author{
Acassia dos Anjos Santos Rosa ${ }^{1}$ \\ Roana Rodrigues ${ }^{2}$
}

\begin{abstract}
Resumo:
Esta pesquisa, de caráter exploratório, apresenta nossos relatos de experiência no que se refere ao uso de instrumentos avaliativos em disciplinas de língua espanhola nos cursos de graduação em Letras de uma universidade federal brasileira. Diante da pandemia do coronavírus e ao novo modelo de ensino (e de profissional) instaurado com as aulas emergenciais remotas, é reconhecida a necessidade de reflexões e ações efetivas em sala de aula, principalmente relacionadas às decisões avaliativas do curso. Desse modo, considerando os aspectos tecnológicos e pedagógicos inerentes ao ensino na modalidade remota, elencaramse as seguintes ações em nosso contexto de atuação: (i) abandono do tradicional "dia de prova"; (ii) propostas de atividades processuais ao longo do semestre; (iii) readequação de atividades gramaticais, proporcionando maior reflexão sobre o ensino e as normas da língua; e (iv) diversificação das atividades avaliativas, com a inclusão de ferramentas tecnológicas para serem realizadas, prioritariamente, em momentos assíncronos. De acordo com a nossa vivência, tais mudanças nos acompanharão também no ensino híbrido e presencial, em um momento pós-pandemia, destacando-se, como transformação relevante, a maior valorização de avaliações do tipo formativas. Este relato contribui com a discussão sobre os métodos e instrumentos avaliativos em diferentes ambientes educacionais, servindo também de referência para propor reflexões e ações na área.
\end{abstract}

Palavras-chave: ensino emergencial remoto; avaliação; espanhol como língua estrangeira.

\begin{abstract}
:
This exploratory research reports our experience with assessment instruments used in Spanish classes from the curriculum of some undergraduate-degree courses in Languages at a Brazilian federal university. With the Covid-19 pandemic and the consequent new teaching and professional - model introduced by emergency remote classes, there is a need for

\footnotetext{
${ }^{1}$ Possui Doutorado em Linguística Aplicada pela Universidade Federal de Minas Gerais (UFMG); Mestrado em Letras pela Universidade Federal de Sergipe (UFS) e Graduação em Letras Português/Espanhol pela mesma instituição. Atualmente é professora Adjunta de Língua Espanhola na UFS onde participa do grupo de pesquisa Diálogos Interculturais e Linguísticos (DinterLin), atuando principalmente nos seguintes temas: formação de professores de espanhol, letramentos críticos, educação intercultural, decolonialidade, América-latina e materiais didáticos. E-mail: acassia.aju@ @otmail.com ORCID https://orcid.org/0000-0002-5858-6628

${ }^{2}$ Doutora e mestra em Linguística pela Universidade Federal de São Carlos (UFSCar); graduada em Letras Português/Espanhol pela mesma instituição. É professora do Departamento de Letras Estrangeiras da Universidade Federal de Sergipe (UFS). Tem interesse pelos seguintes temas de investigação: descrição léxicosintática, estudos descritivos e comparados das línguas portuguesa e espanhola e ensino de espanhol. E-mail roana@academico.ufs.br ORCID https://orcid.org/0000-0002-7748-8716
} 
reflection and effective decision-making in the classroom, mainly concerning the evaluative tools used in the course. Thus, considering technological and pedagogical aspects inherent to remote teaching, the following actions were taken in our context of work: (i) abandoning the traditional "test day"; (ii) proposing process-based activities throughout the semester; (iii) readjusting grammar activities, providing a wider reflection on language teaching and grammar rules; and (iv) providing diversification of assessment activities, with the inclusion of technological tools used, primarily, in asynchronous tasks. According to our experience, such changes will still be used in hybrid and face-to-face classes, in a post-pandemic moment and there will be a greater appreciation of formative-type assessment tools. Therefore, this report contributes to the discussion of assessment and evaluation methods and tools in different educational environments, also serving as a reference to propose reflections and actions in the field.

Keywords: emergency remote teaching; assessment; evaluation; Spanish as a foreign language.

\section{Resumen:}

Esta investigación exploratoria presenta nuestros relatos de experiencia sobre el uso de instrumentos evaluativos en asignaturas de lengua española en cursos de profesorado en Letras de una universidad federal brasileña. Ante la pandemia de coronavirus y el nuevo modelo de enseñanza (y profesional) que se introducen con las clases remotas de emergencia, se reconoce la necesidad de reflexión y acciones efectivas en el aula, principalmente relacionadas a las decisiones evaluativas del curso. Así, considerando los aspectos tecnológicos y pedagógicos inherentes a la enseñanza en la modalidad remota, se enumeraron las siguientes acciones en nuestro contexto de trabajo: (i) abandono del tradicional "día de examen"; (ii) propuestas de actividades continuas a lo largo del semestre; (iii) reajuste de las actividades gramaticales, proporcionando una mayor reflexión sobre la enseñanza y las normas de la lengua; y (iv) diversificación de las actividades de evaluación, con la inclusión de herramientas tecnológicas, para realizarse, principalmente, en momentos asincrónicos. A partir de nuestra experiencia, tales cambios también nos acompañarán en la enseñanza híbrida y presencial, en un momento postpandemia, subrayando, como transformación relevante, la mayor valoración de las evaluaciones formativas. Este trabajo contribuye con la discusión de métodos e instrumentos de evaluación en diferentes entornos educativos, actuando también como referencia para proponer reflexiones y acciones en el área.

Palabras clave: educación remota de emergencia; evaluación; Español como lengua extranjera.

\section{As aulas emergenciais remotas: reflexões iniciais}

A pandemia do coronavírus modificou as relações humanas em diferentes âmbitos. Na educação, verificou-se a necessidade de aderir a aulas emergenciais remotas, como alternativa para manter o distanciamento social e diminuir a possibilidade de contaminação do vírus. $\mathrm{O}$ novo modelo de ensino trouxe consigo inquietações, reflexões e ações efetivas na educação, a partir da mobilização de pesquisadores e professores. 
Muitas dificuldades têm sido enfrentadas nesse novo modelo de ensino (CUNHA et al, 2020; OLIVEIRA et al, 2020; SARAIVA et al, 2020), tais como: o uso das tecnologias por parte de discentes e docentes, a adequação dos conteúdos e avaliações do presencial ao remoto, a possibilidade de acesso aos recursos digitais e, consequentemente, a exclusão social, a ansiedade e a saúde mental, as relações interpessoais mediadas pela tela, entre outras. Em meio a essas questões, surge também um novo profissional do ensino.

Aos poucos, o reconhecimento desse novo profissional tem sido perceptível não só por parte da comunidade escolar, como também da sociedade em geral. Mesmo que timidamente, é possível encontrar discussões na mídia sobre o assunto ${ }^{3}$, assim como a criação e veiculação de memes nas redes sociais. A Figura 1 ilustra a relação da sociedade frente ao novo professor que se instaura na era das aulas remotas, contrastando as dificuldades básicas que o professor tinha até mesmo para usar aparatos simples em sala de aula às habilidades atuais, com o conhecimento e domínio de ferramentas tecnológicas no e para o ensino.

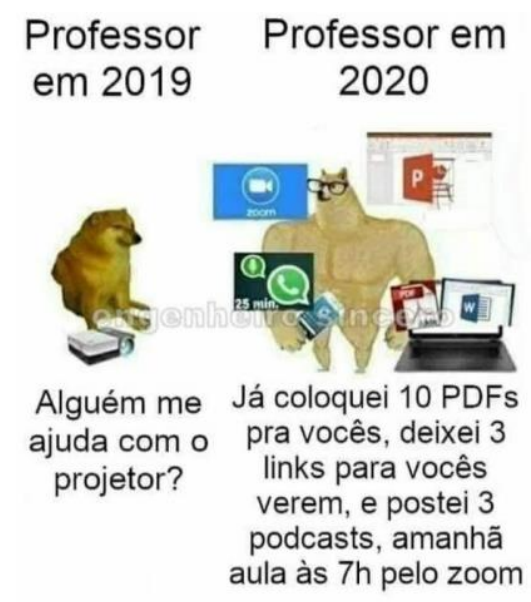

Figura 1: Meme Professor em 2020.

Fonte: FACEBOOK. Disponível em:

https://www.facebook.com/engenheirosincero/photos/a.375180822563855/4234327519982480/?type=3. Acesso em: 30 mai. 2021.

Conforme se verifica na Figura 1, esse novo professor, em pouco tempo, precisou adequar-se às necessidades do momento e dominar, minimamente, recursos tecnológicos para possibilitar a continuidade das aulas em meio à pandemia. Esse processo contou, obviamente,

\footnotetext{
${ }^{3}$ DIÁRIO DO SUDESTE. Notícia sobre as reinvenções do professor com as aulas remotas. Disponível em: https://diariodosudoeste.com.br/pato-branco/professores-se-reinventaram-para-enfrentar-aulas-a-distancia/. Acesso em: 10 jun. 2021.
} 
com muito estudo e dedicação dos profissionais, seja de maneira autodidata, seja a partir da realização de cursos de formação continuada. No entanto, muitas questões ainda têm sido debatidas nesse contexto, incluindo preocupações não só do ensino remoto em si, mas também seus reflexos no ensino presencial que se aproxima.

Iniciamos as reflexões sobre as dificuldades e superações no ensino remoto ainda em 2020. Naquele momento, o uso de softwares de teleconferências, como Google Meet e Zoom, ainda eram uma novidade, pelo menos para nossa realidade educacional. Apresentamos nossos relatos como professoras-pesquisadoras em um curso de extensão (RODRIGUES; ROSA, 2020), em que elencamos dois principais eixos de reflexão: o uso das Tecnologias Digitais de Informação e Comunicação (TDIC) e as adequações de ações pedagógicas, como a quantidade e a seleção e elaboração de materiais, à nova modalidade de ensino.

A partir daquela experiência, concluiu-se que "existem especificidades para a preparação, execução e avaliação de um curso na modalidade remota. Não se trata [portanto] de uma mera transposição do presencial ao remoto" (RODRIGUES; ROSA, 2020, p. 635). Essas reflexões, sem dúvida, nos foram úteis no momento em que tivemos que retomar, também de maneira remota, as aulas em nível de graduação. No entanto, verificamos outras inquietações em nossa prática docente, sobretudo no que diz respeito aos processos avaliativos das disciplinas.

Sendo assim, após mais de um ano de pandemia, dedicamo-nos, neste artigo, a apresentar nosso relato de experiência, do tipo descritivo e exploratório, como docentes nos cursos de graduação em Letras-Espanhol da Universidade Federal de Sergipe (UFS), com ênfase em questões relacionadas aos processos de avaliação dos discentes em disciplinas de língua espanhola. Para tanto, nos baseamos nos conceitos de avaliação (LUCKESI, 2000; MATOS, 2010; AVILA, 2018) e, em discussões conjuntas, refletimos e discorremos, de maneira subjetiva, sobre nossas escolhas avaliativas durante as aulas na modalidade remota. Ao longo das discussões realizadas pelas professoras-pesquisadoras, foi possível encontrar padrões avaliativos (abandono do dia de prova, propostas de atividades processuais, readequação de atividades gramaticais e diversificação das atividades avaliativas), assim como interpretações semelhantes sobre a sua utilização em sala de aula, que serão descritos neste trabalho.

Sendo assim, com o objetivo de contribuir com as discussões pedagógicas sobre as aulas emergenciais remotas e retomar as discussões sobre avaliação, tão importantes no 
processo de ensino e aprendizagem, organizamos este artigo da seguinte maneira: na primeira seção, apresentamos o estado da arte sobre os procedimentos avaliativos e, em seguida, na seção dois, descrevemos especificidades sobre o nosso contexto de atuação. Na seção três, são discutidas as nossas vivências como professoras-pesquisadoras de espanhol como língua estrangeira (ELE) de uma universidade pública, com relação aos procedimentos e instrumentos avaliativos de disciplinas de cunho prático e teórico, comparando, principalmente, as decisões tomadas nas aulas presenciais e as adequações necessárias para o ensino remoto. Por fim, analisamos as nossas práticas e reflexões teóricas, propondo uma possível ressignificação na preparação e avaliação de nossas disciplinas.

\section{Procedimentos avaliativos: revisitando teorias}

Ao longo da história da humanidade, a avaliação era utilizada para mostrar números e realizar classificações, a exemplo da seleção para o ingresso no serviço civil, conforme nos explicita Avila (2018). Dessa forma, os modelos e métodos utilizados na avaliação da aprendizagem se baseavam na classificação dos sujeitos. No Brasil, o ensino jesuítico representa um sistema de avaliação baseado na classificação, no qual os aprendizes são avaliados com exercícios de fixação, por meio da repetição e da memorização.

Os melhores alunos auxiliavam os professores a tomar lições de cor dos outros, recolhendo exercícios e tomando nota dos erros dos outros e faltas diversas que eram chamadas de decuriões. As classes inferiores repetiam lições da semana todo sábado. Daí a expressão "sabatina" utilizada por muito tempo para indicar formas de avaliação (ARANHA, 1989, p. 51 apud AVILA, 2018, p. 55).

Na primeira metade do século XX, com a chegada dos pensamentos da Escola Nova no campo pedagógico brasileiro, a avaliação passa a ser pensada de forma subjetiva, com procedimentos qualitativos que envolvem não apenas professores, mas também os alunos no processo de avaliação. Porém, de acordo com Avila (2018), o pensamento da escolanovista não foi rapidamente incorporado ao sistema educacional brasileiro, prevalecendo as práticas mais tradicionais da avaliação. "A avaliação era baseada em testes padronizados, provas objetivas e outros instrumentos capazes de evidenciar a mudança de comportamento dos aprendizes" (AVILA, 2018. p. 56). O intuito era atribuir à avaliação da aprendizagem um 
rigor científico, menos subjetivo, que pudesse mensurar o conhecimento de igual forma em diferentes indivíduos.

Aos poucos, esse modelo de avaliação tradicional foi sendo repensado. Luckesi (2000) afirma que a avaliação da aprendizagem escolar exige um amplo acompanhamento e reorientação constante. "A avaliação da aprendizagem, por ser avaliação, é amorosa, inclusiva, dinâmica e construtiva, diversa dos exames, que não são amorosos, são excludentes, não são construtivos, mas classificatórios" (LUCKESI, 2000, p. 01). Para o autor, a avaliação é includente e acolhedora, ao contrário, os exames, são excludentes e marginalizadores.

Percebemos, assim, que a discussão sobre os procedimentos e instrumentos avaliativos não é uma novidade nos estudos pedagógicos. De acordo com a concepção de ensino que o professor carrega, os modos de avaliação serão modificados e utilizados a fim de suprir as demandas e objetivos traçados para cada turma. Nesse sentido, a avaliação da aprendizagem pode ser classificada por sua função, sendo as principais: diagnóstica, somativa e formativa. Podemos ainda incluir a autoavaliação como função da avaliação que envolve ativamente a participação do aprendiz.

A avaliação diagnóstica funciona como uma sondagem sobre a aprendizagem do aluno, como ele se desenvolveu, ou não, e como o conhecimento pode ser mais bem socializado, "serve de base para o planejamento das ações de alunos e professores" (AVILA, 2018, p. 72). Essa avaliação pode ser realizada no início de um ciclo de aprendizagem, a fim de, por exemplo, agrupar os estudantes de acordo com seus conhecimentos. Segundo Matos (2011), nas aulas de língua estrangeira, muitas vezes, esse tipo de avaliação serve para nivelar os conhecimentos dos alunos sobre a língua meta e organizá-los de acordo com sua proficiência. Para Luckesi (2000), essa avaliação diagnóstica deve ser estendida durante todo ciclo de aprendizagem, sendo um instrumento de acompanhamento da evolução dos conhecimentos dos estudantes.

Enquanto a avaliação diagnóstica funciona como uma sondagem para repensar as práticas de ensino, a avaliação somativa comumente é realizada na extremidade final do processo de aprendizagem. Ela tem a função de aferir o resultado de uma etapa da aprendizagem, seja o final de uma unidade avaliativa ou mesmo ao final de um curso. No geral, ela indica o fechamento de um ciclo, não sendo utilizada, por exemplo, para aperfeiçoar a educação em seu transcurso. "Essa modalidade de avaliação apresenta um caráter finalista, é 
uma constatação sentenciva, um juízo conclusivo" (GRILLO, 2003 apud AVILA, 2018, p. 72), sendo a verificação pontual do desempenho final de determinado ciclo. Assim, a função somativa da avaliação da aprendizagem, serve, muitas vezes, para atribuir nota a fim de classificar os estudantes ou realizar promoções de um nível para o outro, sem ser possível contribuir de maneira mais efetiva com o seu aprendizado. Essa função é fruto de um modelo tradicional de educação, pouco qualitativa e bastante quantitativo em relação ao aproveitamento dos alunos em determinado processo de aprendizagem.

$\mathrm{Na}$ avaliação formativa, por sua vez, a principal preocupação está no processo de aprendizagem. O professor centra os olhares para o desenvolvimento processual do estudante, analisando com cautela seus erros e acertos, como etapas fundamentais para a construção do saber. Nas aulas de línguas estrangeiras, a análise dos erros é uma etapa fundamental, que deve auxiliar o aluno a superar seus próprios obstáculos no processo da aprendizagem. Dessa forma, os erros devem ser vistos "como efeito da própria prática e de certos procedimentos didáticos, que por isso mesmo precisam ser permanentemente reavaliados" (BRASIL, 2006, p. 143). Nesse sentido, o professor exerce um papel ativo de acompanhamento dos discentes, necessitando utilizar distintos instrumentos avaliativos ao longo do processo.

Por fim, apontamos a autoavaliação como uma função avaliativa que convida o aluno a participar de seu processo de avaliação, fazendo-o olhar para seu próprio progresso. Para Matos (2010) esse tipo de avaliação pode ser bastante motivador, uma vez que o aluno "assume um maior protagonismo em seu processo de aprendizagem e desenvolve a capacidade de seu processo educativo" (p. 272). Dessa forma, para a autora, a autoavaliação possui uma função formativa, pois o aprendiz possui a responsabilidade de realizar uma autorreflexão pessoal sobre seu progresso e suas possíveis dificuldades.

A partir do exposto, é possível perceber que a avaliação possui diversas funções, e de acordo com o modelo de língua e aprendizagem que o professor planeja, é possível se centrar em determinada função avaliativa. De modo geral, é fundamental conhecer as variadas funções avaliativas, a fim de explorar as diversas habilidades que nossos alunos constroem no processo educacional.

A avaliação deve utilizar diferentes instrumentos, tanto para o diagnóstico do progresso do aluno quanto para a mensuração dos resultados alcançados em determinado momento, e deve revestir-se de um caráter positivo de modo a trazer à tona o potencial que o aprendiz tem para avançar no seu estudo da língua estrangeira (BRASIL, 2006, p. 143). 
A partir das avaliações apontadas e considerando as práticas que obtivemos no ensino remoto, ponderamos importante realizar uma avaliação diagnóstica para conhecer os estudantes e, se preciso, realinhar os métodos planejados para determinado ciclo de estudos. Vale ressaltar, que para o ensino de línguas é fundamental uma avaliação processual, que tenha ênfase no processo de aprendizagem dos estudantes, portanto, contínua, formativa, sobretudo em avaliações não-presenciais. Sendo assim, nas próximas seções, apresentaremos nossos relatos de experiência, com o objetivo de contribuir com as reflexões sobre avaliação no ensino emergencial remoto em aulas de língua estrangeira.

\section{Relato de experiência: contexto de atuação}

Neste artigo, apresentamos um relato de experiência, o qual se caracteriza por ser de tipo descritivo e exploratório, narrando, especificamente e de modo subjetivo, as dificuldades e superações enfrentadas em procedimentos avaliativos nas aulas de língua espanhola durante o ensino emergencial remoto na Universidade Federal de Sergipe (UFS). As práticas a serem narradas foram todas criadas pelas professoras autoras deste artigo, com base em suas reflexões e ações pedagógicas ao longo de suas trajetórias como docentes de língua espanhola. Segundo o Anexo I da Resolução no 26/2020/CONEPE da UFS ${ }^{4}$, devido à pandemia e com a aprovação das Atividades Educacionais Remotas Emergenciais da instituição,

as aulas remotas não necessitam ser desenvolvidas sincronamente, no mesmo tempo que aulas presenciais em termos de hora-aula. Cabe uma ressalva no sentido de se garantir encontros síncronos que correspondam a um mínimo $25 \%$ e a um máximo de $50 \%$ da carga horária total do componente, cujos horários previstos para a realização das atividades síncronas deverão ocorrer dentro daqueles informados na oferta da turma. (CONEPE/UFS, 2020, p. 06).

Sendo assim, durante o período de aulas emergenciais remotas, os docentes da universidade precisam preparar aulas síncronas, via Google Meet, não podendo ultrapassar 4 RESOLUÇÃO No 26/2020/CONEPE. Disponível em: https://secretariado.ufs.br/uploads/page_attach/path/10066/Resolu_o_atividades_remotas_informativo_26_202 0.pdf. Acesso em: 10 jun. 2021. 
$50 \%$ da carga horária do curso, assim como atividades para serem desenvolvidas de maneira assíncrona pelos discentes, para suprir a carga horária restante da disciplina. Ademais, a instituição demanda a gravação das aulas, "para o acesso posterior aos recursos e às atividades, de forma que aqueles que tiverem dificuldade no horário fixo possam em momento posterior dispor desse material" (CONEPE/UFS, 2020, p. 17). Parece-nos que essas medidas foram encontradas pela universidade como meios para amenizar possíveis complicações do modelo remoto, no que se refere às limitações de acesso à internet e estabilidade da conexão e ao esgotamento mental e físico, consequência das várias horas em frente às telas.

Para as aulas assíncronas, os docentes devem utilizar como sistema oficial o SIGAA (Sistema Integrado de Gestão das Atividades Acadêmicas), "onde devem ser registradas todas as atividades de planejamento dos processos de ensino-aprendizagem" (CONEPE/UFS, 2020, p. 12). Além disso, a universidade firmou uma parceria com a Google, que permite à comunidade acadêmica ter acesso gratuito às ferramentas do pacote GSuite, o que inclui a criação de documentos, formulários, videochamadas, entre outros.

Em nosso contexto de atuação, o docente tem autonomia para a seleção e elaboração de materiais utilizados em suas disciplinas, seguindo as diretrizes das ementas do curso. Sendo assim, os procedimentos e instrumentos avaliativos também são escolhidos pelo professor, de acordo com as suas crenças e necessidades. Neste trabalho, focamos em compartilhar ações avaliativas das disciplinas de Teoria e Prática de Língua Espanhola I e III, Língua Espanhola VI e Lexicografia dos cursos de Letras, com habilitação em língua espanhola, realizadas nos dois semestres letivos de 2020. De antemão, pode-se afirmar que as práticas avaliativas foram refletidas e ressignificadas nesse modelo de ensino remoto, com ações que serão descritas na próxima seção.

\section{Avaliação nas aulas de ELE no ensino superior: reflexões no ensino emergencial remoto}

Conforme relatamos em Rodrigues e Rosa (2020), as aulas emergenciais remotas evidenciam a necessidade de adequações no que se refere, grosso modo, aos aspectos tecnológicos e pedagógicos. Sobre a tecnologia, é preciso considerar a possibilidade de conexões instáveis (dos discentes e do próprio docente) e o uso de ferramentas bem 
selecionadas, delimitadas e de fácil utilização. Já com relação às questões pedagógicas, é importante a preparação de um plano de atividades bem delineado que, ao mesmo tempo, seja flexível e permita modificações ao longo do curso; instruções detalhadas; seleção de exercícios que promovam a autonomia dos estudantes; consideração da quantidade de atividades solicitadas, tendo em vista as limitações interativas do modelo que privilegia, de maneira geral, a comunicação escrita; além da reformulação das avaliações do curso, que não podem contemplar, por exemplo, a participação "presencial" dos discentes nas aulas síncronas.

Essas reflexões, como já relatado, foram consequências de experiências em uma ação de extensão. Com o início das aulas emergenciais remotas, em nível de graduação, as professoras-pesquisadoras seguiram com suas práticas reflexivas e, então, puderam identificar um novo aspecto sobressalente, característico de disciplinas obrigatórias: os procedimentos e instrumentos avaliativos e, por conseguinte, as atividades e critérios para a aprovação ou retenção dos estudantes. É importante salientar que tais critérios são variados, a depender dos objetivos da disciplina e dos instrumentos avaliativos utilizados. No entanto, esses critérios foram sempre explicitados aos discentes com antecedência e consideraram, de maneira geral, o envolvimento, a participação e a assiduidade do estudante na disciplina, além de sua adequação à atividade proposta e ao gênero discursivo e o desempenho em língua espanhola.

Considerando a preocupação das docentes, iniciou-se uma série de propostas avaliativas, na tentativa de encontrar ações significativas para a formação dos graduandos em tempos de pandemia. Como consequência - e a partir de reflexões e diálogos realizados pelas professoras -, foram listados quatro aspectos que, a nosso ver, são relevantes e podem atuar como questões condutoras a outros profissionais e contextos de ensino e aprendizagem de línguas, a saber: (i) abandono do "dia de prova"; (ii) propostas de atividades processuais; (iii) readequação de atividades gramaticais; e (iv) diversificação das atividades avaliativas.

\section{Abandono do dia de prova}

Segundo Matos (2010), a avaliação somativa pode apresentar informações importantes sobre o processo de aprendizagem do estudante, no entanto, é um erro limitar-se somente a ela, desconsiderando toda a trajetória percorrida pelo aluno ao longo da disciplina. Um instrumento tipicamente associado à avaliação somativa é o "dia de prova", em que o 


\section{OO DEVIR EDUCAÇÃO}

ISSN: 2526-849X

estudante precisa responder a uma série de questões, normalmente sem consultar os materiais estudados, em um dia pré-determinado, para demonstrar domínio sobre os temas trabalhados ao longo do bimestre ou semestre.

Nas aulas remotas, dificuldades como a instabilidade da conexão, a invasão da privacidade - que mescla o espaço pessoal de estudo com a sala de aula -, além de assuntos relacionados à saúde mental dos estudantes, como a ansiedade e a timidez, nos fazem questionar sobre a persistência do modelo tradicional de "dia de prova", ainda tão frequente no ensino presencial. Posto isso, parece-nos importante mencionar que, inclusive para os docentes que mantêm o "dia de prova" nas aulas remotas, é necessário considerar a revisão crítica desse modelo, de acordo, obviamente, com o seu contexto de atuação.

Enfatizamos a necessidade de reflexão sobre o contexto, porque o abandono de avaliações do tipo "dia de prova", em nosso caso, deveu-se, principalmente, a relatos realizados pelos próprios discentes sobre as dificuldades enfrentadas para manter-se conectados em momentos síncronos e assíncronos das disciplinas. Portanto, a exigência de um dia e horário específicos para a realização de uma atividade avaliativa, sobretudo do tipo "teste", geraria um ambiente de maior dificuldade e, até mesmo, de exclusão para nossos discentes.

Uma segunda questão relevante para a decisão de focar em avaliações de caráter formativo foi a necessidade de um bom e detalhado planejamento de curso, com o intuito de, principalmente, auxiliar os estudantes em sua própria organização de estudos. Como sabido, o modelo remoto é marcado por uma maior responsabilidade, comprometimento e autonomia do alunado (SARAIVA et al, 2020), no entanto, a construção dessa "independência" do estudante demanda tempo, compreensão adequada das instruções dadas na disciplina e muita organização. Sendo assim, verificou-se que, quando eram solicitados aos estudantes determinados exercícios e leituras acadêmicas, sem a necessidade de envio de suas conclusões, muitos admitiam não realizarem tais atividades. Ou seja, a solicitação de exercícios importantes, mas não "pontuados" nas disciplinas, eram ignorados, provavelmente devido às prioridades dadas pelos alunos às atividades que "valiam nota". Portanto, propostas de atividades avaliativas (e pontuadas) nos momentos assíncronos do curso tornaram-se um meio de contribuir tanto com o aprendizado formativo do discente, como com a sua organização de estudos. Isso já nos introduz ao segundo aspecto elencado neste trabalho: as propostas de atividades processuais. 


\title{
Propostas de atividades processuais
}

As atividades avaliativas processuais são as que ocorrem ao longo do processo de aprendizagem e possuem uma função formativa, em outras palavras, ajudam o aluno a aprender durante o transcurso das aulas, na medida em que evidencia seus erros e acertos em tempo hábil de repensá-los.

Como um exemplo do que nomeamos atividade processual, descrevemos as ações realizadas na disciplina de Lexicografia (de apenas dois créditos), em que foram propostas duas avaliações: (i) realização de atividades nas aulas assíncronas, ao longo do semestre; e (ii) escrita de um trabalho acadêmico com a análise da macro e microestrutura de dicionários eletrônicos.

Trata-se de uma atividade processual, porque os estudantes tinham tarefas de leituras acadêmicas e, além disso, precisavam realizar breves atividades avaliativas a partir do uso de diferentes instrumentos (questionário, elaboração de resumo ou participação em fóruns). Esse tipo de proposta avaliativa segue os pressupostos da metodologia ativa da sala de aula invertida, em que

\begin{abstract}
o conteúdo e as instruções recebidas são estudados on-line, antes de o aluno frequentar a aula, usando as TDIC, mais especificamente, os ambientes virtuais de aprendizagem. A sala de aula torna-se o lugar de trabalhar os conteúdos já estudados, realizando atividades práticas como resolução de problemas e projetos, discussão em grupo e laboratórios. No entanto, o fato de as atividades que o estudante realiza on-line poderem ser registradas no ambiente virtual de aprendizagem cria a oportunidade para o professor fazer um diagnóstico preciso do que o aprendiz foi capaz de realizar, as dificuldades encontradas, seus interesses e as estratégias de aprendizagem utilizadas. Com base nessas informações, o professor, juntamente com o aluno, pode sugerir atividades e criar situações de aprendizagem totalmente personalizadas (VALENTE, 2018, p. 27).
\end{abstract}

Sendo assim, nas aulas assíncronas, os estudantes tinham tarefas quinzenais de leitura e realização de uma breve atividade avaliativa e os encontros síncronos, por sua vez, eram dedicados para tirar dúvidas, discutir as respostas e a participação dos estudantes nos momentos assíncronos, além do aprofundamento das discussões teóricas propostas.

Embora a segunda avaliação da disciplina (elaboração de um trabalho acadêmico) se assemelhe a um instrumento característico de avaliações somativas, a consideramos como 
uma atividade também de cunho formativo. Inclusive, salientamos essa experiência, não só pelo parecer positivo do modelo de sala de aula invertida - já conhecido e previamente utilizado pelas docentes até mesmo nas aulas presenciais -, mas, sobretudo, pela relação estabelecida entre a primeira e segunda avaliações do curso.

Para a elaboração da segunda avaliação, os discentes precisaram colocar em prática todas as discussões teóricas e práticas realizadas ao longo do semestre e realizaram um trabalho final, em dupla, no qual demonstravam os conhecimentos adquiridos na elaboração de um artigo científico, gênero tão relevante para a sua formação acadêmica. A docente ressaltou a qualidade dos textos produzidos, que relacionaram adequadamente teoria e prática lexicográficas.

Em nosso contexto, nomeamos esse tipo de atividade avaliativa como processual, e destacamos a sua relevância, principalmente em disciplinas teóricas, por estabelecer relações entre os conteúdos trabalhados no curso; contribuir com a organização dos estudantes, no sentido de ordenar e distribuir as demandas obrigatórias da disciplina ao longo de todo o semestre; e possibilitar a união entre a teoria e a prática, com os momentos de leitura, discussão e produção de texto acadêmico na área.

\section{Readequação de atividades gramaticais}

Sobre a readequação de atividades gramaticais, enfatizamos nossas experiências vivenciadas nas disciplinas de Teoria e Prática de Língua Espanhola I e Língua Espanhola VI. Em nossa prática, nos preocupamos em proporcionar uma formação cidadã e crítica a nossos estudantes, futuros professores do ensino básico em nosso país. Sendo assim, pretendemos oferecer subsídios para que "eles possam atuar no ensino básico com a língua espanhola como meio de inclusão social, de maneira que a língua não seja vista como um mero sistema e passe a ser vivida como promovedora de práticas de linguagem situadas socio/historicamente" (ROSA; MATOS, 2020, p. 28). Assim, os graduandos precisam conhecer a língua em todos os seus aspectos, não descartando a prática gramatical em um estudo situado.

No ensino presencial, muitas das práticas de uso de aspectos gramaticais trabalhados na disciplina acontecem em grupos ou duplas durante a própria aula, além da realização de atividades a serem feitas em casa. No entanto, conforme advertido em Rodrigues e Rosa (2020), as interações simultâneas nas aulas remotas síncronas, principalmente as orais e em 
grupos mais numerosos, são raras ou possuem várias dificuldades para sua realização, novamente devido a restrições características desse modelo de ensino, tais como: instabilidade de conexão, falta de recursos como câmera e microfone, questões emocionais, como timidez, entre outros.

Por isso, no ensino remoto, as nossas práticas de uso de aspectos gramaticais da língua são delegadas, de maneira geral, aos momentos assíncronos, exigindo organização e responsabilidade dos estudantes para a realização das atividades solicitadas. No entanto, o distanciamento físico do ensino remoto dificulta a avaliação do desempenho dos alunos, no que se refere mais especificamente à realização de exercícios gramaticais, o que implica em novas formas de discutir essas atividades em sala de aula, especialmente nos cursos de graduação em Letras.

Em um primeiro momento, buscou-se solicitar aos estudantes o envio de uma imagem da tela do dispositivo eletrônico, que "comprovasse" a realização das atividades. Essa estratégia foi utilizada para os estudantes do primeiro semestre do curso, na disciplina Teoria e Prática de Língua Espanhola I. Contudo, ao nos questionarmos sobre a efetividade de tal “comprovação" para o real aprendizado dos alunos, sobretudo para os licenciandos mais avançados no curso, optamos por uma nova abordagem, na qual mantivemos as recomendações de exercícios gramaticais de língua espanhola, mas solicitamos a sua discussão em fóruns abertos na plataforma de uso assíncrono (SIGAA).

$\mathrm{Na}$ disciplina de Língua Espanhola VI, por exemplo, a professora solicitou aos estudantes que realizassem os exercícios de uma Unidade Didática Interativa proposta e disponível no site ProfedeEle ${ }^{5}$, para praticar o conteúdo teórico-prático já discutido em aulas síncronas. Em seguida, os discentes deveriam participar de um fórum, no qual apresentariam uma breve definição do assunto tratado e discutiriam os aspectos positivos da Unidade, além de proporem alterações e/ou inclusões a ela, imaginando o uso de tais atividades em uma situação de ensino na educação básica.

Essa atividade possibilitou a união de duas questões concernentes à formação de nossos estudantes: o aprendizado de espanhol como língua estrangeira e as discussões sobre o papel do docente na seleção e elaboração de atividades didáticas. Assim, a partir dessa tarefa foi possível desenvolver reflexões não só sobre o conteúdo do curso, mas também estabelecer relações com outras disciplinas do currículo, como Estágio Supervisionado, e com os

\footnotetext{
${ }^{5}$ PROFEDEELE. Disponível em: https://www.profedeele.es/. Acesso em: 10 jun. 2021.
} 
programas institucionais de formação à docência desenvolvidos em nosso Departamento, como PIBID ${ }^{6}, \mathrm{RP}^{7}$ e PROLICE ${ }^{8}$.

Reiteramos, assim, a necessidade de haver um momento para a estruturação de aspectos linguísticos nas aulas de língua e a possibilidade de encontrar alternativas não só para a sua ("comprovação" de) realização, como também a sua reflexão no ensino superior, pensando, efetivamente, na formação docente de estudantes de cursos de licenciatura.

\section{Diversificação das atividades avaliativas}

Conforme apontado ao longo do artigo, o ensino remoto trouxe consigo a preocupação sobre os métodos e instrumentos avaliativos de maneira geral. Sendo assim, nosso relato demonstra que a diversidade avaliativa é um aspecto fundamental para promover o avanço das discussões do curso e a disciplina e participação dos estudantes. $\mathrm{O}$ abandono do dia de prova e a sua substituição por atividades do tipo processuais, já ilustram o que aqui chamamos por diversificação das atividades. A fim de exemplificar algumas decisões que visaram a ampliação dos instrumentos avaliativos, descrevemos as ações de avaliação da oralidade nas disciplinas de Teoria e Prática de Língua Espanhola I e III.

A avaliação da oralidade foi um desafio à parte no ensino remoto, principalmente considerando as especificidades de um curso de formação de professores de espanhol. No ensino presencial, nas disciplinas iniciais e nas de prática de língua espanhola, costumamos avaliar os discentes pela participação constante nas aulas, além de realizar entrevistas ao final da disciplina para aferir a fluência no idioma estudado. Essa última estratégia, muitas vezes, se aproxima da função somativa da avaliação, visto que o discente é posto à prova no final do semestre, sem muito tempo para reorientações dentro da própria disciplina. Para as disciplinas de Teoria e Prática de Língua Espanhola I e III, no momento da elaboração, pensamos em manter as tradicionais entrevistas para cada disciplina. Porém, considerando a experiência na instabilidade da conexão dos alunos no curso de expressão escrita ministrado (RODRIGUES;

\footnotetext{
${ }^{6}$ PIBID (PROGRAMA INSTITUCIONAL DE BOLSAS DE INICIAÇÃO À DOCÊNCIA). Disponível em: http://portal.mec.gov.br/pibid. Acesso em: 10 jun. 2021.

7 RP (RESIDÊNCIA PEDAGÓGICA). Disponível em: https://www.gov.br/capes/pt-br/acesso-ainformacao/acoes-e-programas/educacao-basica/programa-residencia-pedagogica. Acesso em: 10 jun. 2021.

8 PROLICE (PROJETO APOIO PEDAGÓGICO LICENCIANDOS NA ESCOLA). Disponível em: https://prograd.ufs.br/pagina/22723-projeto-licenciandos-as-na-escola-prolice. Acesso em: 10 jun. de 2021.
} 
ROSA, 2020), optamos por diversificar as formas de acompanhamento do desenvolvimento dos estudantes.

Um ponto positivo foi que cada disciplina contava com dois monitores, licenciandos que já cursaram os componentes e foram selecionados por edital para acompanhar e contribuir com as atividades da disciplina, com a intenção de exercitar os conhecimentos adquiridos e auxiliar na aprendizagem dos discentes inscritos. Dessa forma, os monitores criaram grupos na plataforma de mensagens instantâneas, WhatsApp, e buscaram motivar os estudantes a praticarem oralmente o idioma, por meio de áudios com comentários dos conteúdos e temas vistos em classe. Assim, os estudantes matriculados nas disciplinas tinham uma atenção e assistência assíncronas, em momentos posteriores às aulas.

A partir de tais interações, os alunos deveriam gravar vídeos, semelhantes a YouTubers e postar na plataforma para avaliação da professora no início do último mês do curso. Os vídeos gravados pelos discentes da disciplina Teoria e Prática de Língua Espanhola I, de temática livre, deveriam possuir caráter mais descritivo de seus gostos e costumes; já os alunos da disciplina Teoria e Prática de Língua Espanhola III deveriam gravar um vídeo que tratasse de alguns dos temas vistos em sala (racismo, machismo, diversidade, pluralidade cultural, entre outros) associado a alguma obra cultural, fosse uma poesia, livro, filme ou série.

Nos grupos do WhatsApp, os discentes eram orientados pelos monitores sobre o recorte da temática escolhida, como também questões relativas à estrutura da língua e à oralidade. Assim, os discentes poderiam gravar e regravar os vídeos, até a entrega final, seguindo as instruções da atividade (tempo de gravação, critérios de correção e estrutura/partes do vídeo). Além disso, os estudantes que foram avaliados com uma nota menor que a média do valor da atividade, puderam realizar uma nova gravação, com uma orientação específica sobre os pontos que deveriam ser aperfeiçoados. Esse foi um modo de atribuir ao processo de gravação do vídeo uma função formativa da avaliação, que iniciou com o acompanhamento das aulas, as interações no grupo do Whatsapp com os monitores até a reelaboração da atividade pelos alunos que não alcançaram o objetivo final proposto pela docente, tendo uma nova oportunidade de reflexão sobre seu processo de aprendizagem.

O resultado foi a elaboração de vídeos criativos, interativos, adequados à proposta, ao gênero e à língua espanhola em sua variante culta. Além disso, houve a exploração do uso das tecnologias com diversos efeitos e edição midiática, o que demonstrou a conexão dos 
estudantes com a disciplina, expressando-se desde um ponto de vista pessoal. Ressaltamos que em ambas as propostas era possível que o estudante incluísse aspectos de seus gostos, sendo possível que o professor pudesse se conectar melhor com esses estudantes, mesmo que na reta final da disciplina.

Salientamos que uma avaliação processual, que possa oferecer um feedback para os estudantes, requer mais atenção e dedicação e, consequentemente, demanda mais trabalho para o professor. Com isso, ponderamos que, tanto no curso de extensão, como nas disciplinas de Teoria e Prática de Língua Espanhola I e III, contamos com turmas reduzidas (cerca de 30 estudantes no curso e 20 estudantes em cada disciplina), além de mais de um profissional para realizar o acompanhamento das atividades dos aprendizes, sendo no curso duas professoras e nas disciplinas, uma professora e dois monitores em cada componente.

\section{Considerações finais}

As disciplinas oferecidas no ensino remoto tiveram que ser elaboradas pensando em falhas na comunicação que o ensino presencial não oferece. Dessa forma, esse ensino exigiu mais dedicação do professor, principalmente no momento da elaboração e acompanhamento das atividades. Os alunos, por sua vez, também foram desafiados a participar mais e de maneira mais diversa, fosse nos chats, durante as aulas síncronas, fosse nas diferentes atividades e nos diferentes instrumentos avaliativos selecionados, nos momentos assíncronos.

Atividades que antes, no ensino presencial, eram realizadas em sala, no ensino remoto, passaram a ser realizadas nas aulas assíncronas, muitas vezes sem a possibilidade do acompanhamento do professor, exigindo dos alunos maior autonomia e um processo de reflexão sobre o exercício antes de sua conclusão. Nesse sentido, a avaliação processual, com função formativa, ganhou mais espaço no ensino remoto, promovendo uma diversidade nos instrumentos de avaliação. O distanciamento físico e as questões tecnológicas levaram ao afastamento de um dia específico de prova, o qual poderia não ser efetivo, pela possibilidade de cópias (entre os estudantes) e a incerteza e insegurança quanto ao acesso estável à internet.

Embora não tenha sido o foco de nosso relato, a autoavaliação também sempre esteve em nossa prática docente, como mais um modo avaliativo de fomentar o caráter formativo de nossos cursos. Principalmente nos momentos finais das disciplinas, realizamos rodas de debate para discutir com os estudantes a disciplina em si e a participação, dedicação e 


\section{OO DEVIR EDUCAÇÃO}

ISSN: 2526-849X

aprendizado de cada um. Isso tem servido para promover a reflexão da atuação dos discentes e das posteriores práticas docentes. Inclusive, algumas das propostas avaliativas descritas nesta investigação foram consequência desses momentos de autoavaliação em disciplinas anteriores.

Concluímos que, em nossa experiência, destacamos a avaliação assíncrona como forma de abranger um maior número de estudantes, com o abandono do "dia de prova" e propostas de atividades processuais, que possibilitam ao estudante ter respostas sobre seu percurso da aprendizagem. Além disso, salientamos a readequação de atividades gramaticais, que proporcionam aos alunos uma participação mais ativa e reflexiva com seu próprio processo de aprendizagem, mobilizando outros conhecimentos, além do gramatical; e a diversificação das atividades avaliativas, que busca envolver os discentes em atividades significativas em tempos remotos.

Os resultados das avaliações foram positivos, no sentido de evidenciarem o avanço do conhecimento por parte dos alunos, no que diz respeito à adequação à norma culta da língua espanhola, ao gênero discursivo trabalhado e aos demais conteúdos estudados em sala de aula. Os aspectos positivos também foram explicitados pelos próprios estudantes, em momentos de autoavaliação durante e, sobretudo, ao final das disciplinas.

A intenção deste relato foi a de compartilhar com a comunidade as mudanças e decisões tomadas em nosso contexto de atuação. No entanto, reconhecemos a necessidade de desdobramentos sobre essas questões, em investigações futuras, as quais se baseiem em dados mensuráveis que explicitem as diferenças reais entre os métodos e instrumentos avaliativos tradicionais e as alternativas escolhidas durante a pandemia.

Acreditamos que este relato pode servir de inspiração para outros profissionais de ensino que precisam ressignificar e refletir sobre suas próprias práticas docentes e, de maneira muito veloz, adaptar-se às novas demandas que surgem com a pandemia e o ensino remoto, tornando-se um novo profissional. Essas reflexões, seguramente, nos acompanharão em nossas práticas, quando toda a comunidade acadêmica, devidamente vacinada, voltar aos encontros presenciais nas dependências físicas da universidade.

\section{Referências}


AVILA, A. P. A avaliação no ensino de espanhol: crença-ação de duas professoras da escola pública. Tese de Doutorado. Universidade Federal de Santa Maria. Curso de Letras e Artes. Programa de Pós-Graduação em Letras, RS, 2018.

BRASIL. Orientações curriculares para o ensino médio: Linguagens, códigos e suas tecnologias / Secretaria de Educação Básica. Conhecimentos de língua estrangeira - espanhol Brasília: MEC/SEMTEC, 2006.

CONEPE/UFS. Resolução no 116/2006. Dispõe sobre as Atividades de Extensão e institui o Programa de Apoio à Extensão na Universidade Federal de Sergipe. 2006. Disponível em: https://proex.ufs.br/uploads/page_attach/path/6627/resconep_116.2006_0.pdf. Acesso em: 30 ago. 2021.

CUNHA, L. F. F.; SILVA, A. S.; SILVA, A. P. O ensino remoto no Brasil em tempos de pandemia: diálogos acerca da qualidade e do direito e acesso à educação. Revista Com Censo, v. 7 , n. 3, p. 27-37, 2020. Disponível em: http://periodicos.se.df.gov.br/index.php/comcenso/article/view/924. Acesso em: 30 ago. 2021.

LUCKESI, C. C. O que é mesmo o ato de avaliar a aprendizagem? Revista Pátio. Porto Alegre: ARTMED. A. 3, n. 12, fev./abr. 2000. Disponível em: https://www.nescon.medicina.ufmg.br/biblioteca/imagem/2511.pdf. Acesso em: 30 ago. 2021.

MATOS, D. C. V. S. A avaliação no ensino de ELE. In: BARROS, C. S.; COSTA, E. G. M. (Coords.). Espanhol: ensino médio. Brasília: Ministério da Educação, Secretaria de Educação Básica, 2010. p. 265-279. Disponível em: http://portal.mec.gov.br/docman/abril2011-pdf/7836-2011-espanhol-capa-pdf/file. Acesso em: 30 ago. 2021.

OLIVEIRA, S. S.; SILVA, O. S. F.; SILVA, M. J. O. Educar na incerteza e na urgência: implicações do ensino remoto ao fazer docente e a reinvenção da sala de aula. Interfaces Científicas, v. 10, n. 1 , p. 25-40, 2020. DOI: https://doi.org/10.17564/2316$\underline{3828.2020 \mathrm{v} 10 \mathrm{n} 1 \mathrm{p} 25-40 .}$.

RODRIGUES, R.; ROSA, A. A. S. Curso de produção escrita em espanhol como língua estrangeira na modalidade remota. Revista (con)textos linguísticos, v. 14, n. 29, p. 623 - 638, 2020. DOI: https://doi.org/10.47456/cl.v14i29.32152.

ROSA, A. A. S.; MATOS, D. C. V. PIBIB e RP: um olhar de professores de espanhol em formação na UFS. Revista do GELNE, v. 22, n. 2, p. 26-38, 2020. https://doi.org/10.21680/1517-7874.2020v22n2ID19412.

SARAIVA, K.; TRAVERSINI, C. LOCKMANN, K. A educação em tempos de COVID-19: ensino remoto e exaustão docente. Práxis Educativa (IMPRESSO), v. 15, p. 1-24, 2020. DOI: https://doi.org/10.5212/PraxEduc.v.15.16289.094.

VALENTE, J. A. A Sala de aula invertida e a possibilidade do ensino personalizado: uma experiência com a graduação em midialogia. In: BACICH, L.; MORAN, J. (Orgs.). Metodologias ativas para uma educação inovadora: uma abordagem técnico-prática. Porto Alegre: Penso, 2018. 
Recebido em 12-07-21

Aprovado em 28-08-21

Revista Devir Educação, Lavras-MG. Edição Especial, p.303-322, Set./2021. 